\title{
Navigational bronchoscopy specimens and PD-L1 expression: a retrospective study
}

\author{
Hussein Asad ${ }^{1}$, Timothy Saettele ${ }^{2}$, Ossama Tawfik ${ }^{3}$, Philip Jones ${ }^{4}$, Matthew Aboudara ${ }^{2}$ \\ ${ }^{1}$ Department of Pulmonary and Critical Care, University of Missouri-Kansas City School of Medicine, Kansas City, MO, USA; ${ }^{2}$ Division of \\ Pulmonary and Critical Care, Saint Luke's Health System, Frank and Evangeline Thompson Thoracic Center, Kansas City, MO, USA; ${ }^{3}$ Department \\ of Pathology, Saint Luke's Health System, Kansas City, MO, USA; ${ }^{4}$ Deparment of Cardiovascular Research, Saint Luke's Health System, Kansas \\ City, MO, USA \\ Contributions: (I) Conception and design: M Aboudara, H Asad, P Jones; (II) Administrative support: P Jones; (III) Provision of study materials or \\ patients: M Aboudara, T Saettele; (IV) Collection and assembly of data: M Aboudara, H Asad, O Tawfik; (V) Data analysis and interpretation: All \\ authors; (VI) Manuscript writing: All authors; (VII) Final approval of manuscript: All authors. \\ Correspondence to: Matthew Aboudara, MD, FCCP, DAABIP. Division of Pulmonary and Critical Care, Saint Luke's Health System, Frank and \\ Evangeline Thompson Thoracic Center, Kansas City, MO 64111, USA. Email: maboudara@saint-lukes.org.
}

\begin{abstract}
Background: Additional data regarding the ability of navigational bronchoscopy (NB) to provide sufficient material for programmed death-ligand 1 (PD-L1) expression is needed. We performed a retrospective study of NB cases at our institution to determine performance of NB in providing adequate samples for PD-L1.

Methods: We conducted a retrospective review of all consecutive NB procedures performed at our institution from January 1, 2018 to August 4, 2020 that involved biopsies of a lung nodule/mass with a diagnosis of non-small cell lung cancer (NSCLC). The primary outcome was adequacy of material for PD-L1 testing. All procedural, demographic, and diagnostic data were collected. The association of factors with PD-L1 adequacy was evaluated with rate ratios (RR) using modified Poisson regression models with robust standard errors.

Results: A total of 102 NB procedures with a diagnosis of NSCLC were performed over a 2-year period. The mean [standard deviation (SD)] nodule size was 25.0 [interquartile range (IQR), 18.0-32.0] mm and $57.8 \%$ (59/102) had a bronchus sign; 73\% (68/93, 9 missing data) of samples were adequate for PD-L1 testing. Radial endobronchial ultrasound (REBUS) was utilized in 99\% (101/102) of biopsies; a concentric or eccentric view was observed in $78.2 \%(79 / 101)$ and $16.8 \%(17 / 101)$, respectively. Transbronchial biopsy (TBBX) was performed in 92.2\% (94/102). Only 4\% (4/102) of cases required additional biopsies with either computed tomography (CT) guided transthoracic or surgical biopsies due to insufficient bronchoscopy tissue. No factors were predictive of PD-L1 adequacy in regression models.

Conclusions: NB demonstrated good performance in obtaining adequate samples for PD-L1 testing. Only $4 \%$ of patients required additional procedures for more tissue when clinically indicated. However, additional study is needed to validate these results against surgical resection specimens.
\end{abstract}

Keywords: Bronchoscopy; lung neoplasms; non-small cell lung cancer (NSCLC); biopsy

Submitted Sep 11, 2021. Accepted for publication Jan 07, 2022.

doi: $10.21037 /$ jtd-21-1454

View this article at: https://dx.doi.org/10.21037/jtd-21-1454

\section{Introduction}

The utilization of immune checkpoint inhibitors has revolutionized care given to patients with non-small cell lung cancer (NSCLC) with several anti-programmed death-ligand 1 (PD-L1) monoclonal antibodies available as a first- or second-line therapy (1-5). Most published clinical trials evaluating the clinical efficacy of antiPD-L1 agents included only computed tomography (CT) 
guided core needle or surgical biopsy specimens. As a result, little information is known regarding the utility of small non-surgical biopsy samples, such as navigational bronchoscopy (NB), in obtaining sufficient tissue for PDL1 analysis (6). There have been concerns that small biopsy samples may either (I) obtain low tumor volume samples and (II) inaccurately report PD-L1 expression due to intratumor heterogeneity (ITH) and lack of preserved tissue architecture $(6,7)$. As such, it is imperative that bronchoscopy biopsy procedures demonstrate sufficient tissue acquisition to process samples for PD-L1 expression.

Data has suggested that advanced molecular profiles (EGFR, KRAS, ALK, BRAF) can be obtained in up to $80 \%$ of bronchoscopy specimens from either radial endobronchial ultrasound (REBUS) guided or electromagnetic navigation bronchoscopy (ENB) guided biopsies of peripheral lung NSCLC $(8,9)$. These bronchoscopy obtained samples have also shown excellent concordance with surgical biopsy specimens with one study demonstrating $86.6 \%$ concordance between cytological and histological specimens for KRAS and EGFR (10).

However, little has been reported on performance of bronchoscopy in tissue acquisition of PD-L1 samples. In one study of radial ultrasound guided (REBUS) transbronchial biopsies of peripheral lung nodules, PD-L1 was successfully performed on $94 \%$ of samples tested. However, only $16 \%$ of the total study population who underwent bronchoscopy had PD-L1 tested (11). Additionally, two studies reported conflicting results on concordance rates between bronchoscopy and surgical biopsy PD-L1, with one reporting a $92.4 \%$ concordance while another reporting only a $52 \%$ concordance between the two different specimens $(12,13)$. A recent study by Robin et al. (14) reported $94 \%$ PD-L1 feasibility of specimens obtained by REBUS; however approximately $65 \%$ of patients had advanced stage disease with lesions greater than $3 \mathrm{~cm}$ and factors associated with sample adequacy was not reported. Thus, the overall adequacy of samples across a heterogenous population, factors predictive of sample adequacy, and their accurate representation of intratumor PD-L1 expression obtained by bronchoscopy remains unknown.

In order to better understand the performance and limitations to NB for PD-L1, we performed a retrospective study of consecutive NB procedures at our institution in order to assess the performance of $\mathrm{NB}$ on acquisition of sufficient tissue for PD-L1 expression and factors associated with specimen adequacy. We present the following article in accordance with the STROBE reporting checklist (available at https://jtd.amegroups.com/article/view/10.21037/jtd-211454/rc).

\section{Methods}

We conducted a retrospective review of all consecutive NB procedures performed at our institution from January 1, 2018 to August 4, 2020 that involved bronchoscopic biopsies of a lung nodule or mass and had a diagnosis of NSCLC. This study was approved by Saint Luke's Health System Institutional Review Board (IRB \#SLHS-20-118) and was conducted in accordance with the Declaration of Helsinki (as revised in 2013). Informed consent was waived due to the retrospective nature of the study. The definition of a NB procedure included either (I) the use of REBUS plus fluoroscopy or (II) use of an ENB platform. The SuperDimension 7.0 (Medtronic, Plymouth, MN, USA) navigation system was used for all ENB procedures. This definition was used to ensure that all diagnostic bronchoscopy procedures for a PPN were retrospectively captured from our dataset as a different technology may have been chosen to biopsy the target lesion based upon size, location, or presence of a bronchus sign.

The primary outcome was defined as sample adequacy to process for PD-L1 (Yes/No). All PD-L1 processing occurred internally. A PD-L1 rabbit monoclonal in vitro diagnostic antibody was used for immunohistochemistry assessment of PD-L1 cell membrane expression on NSCLC specimens. For immunohistochemistry staining, our pathology department utilizes a SP263 clone as part of the OptiView Detection kit (Rosche Diagnostics, Indianapolis, IN, USA). The comparable performance of SP263 clone versus 22C3 and $28-8$ has been previously validated $(15-17)$. The percent immunoreactivity of tumor cells and immune cells were evaluated by manual microscopy. For the primary outcome, a sample was considered adequate for PD-L1 if a report was generated that reported a percentage of PD-L1 expression. In contrast, a sample was considered not adequate if the pathology report stated that there were insufficient tumor cells to evaluate PD-L1 expression. If no PD-L1 status was reported despite a confirmed diagnosis of NSCLC, the data was considered missing. Samples were processed for PD-L1 if there was a minimum of identifiable 200 or more tumor cells within the specimen by the immunohistochemistry staining method. However, as per standard institutional practice, it was left to the discretion of the pathologist to process specimens with tumor cell count between 100-200 if it was felt that a robust percentage of viable tumor cells were identified. 
Secondary outcomes determined a priori included adequacy for molecular and next generation sequencing (NGS); requirement for a second biopsy procedure for additional tissue; and concordance of NB guided tissue samples versus surgically collected specimens for PD-L1 expression. However, since our institution only performs PD-L1 testing on one biopsy specimen (bronchoscopy, CTguided, or surgical), very limited data was available for the $\mathrm{NB}$ versus surgical concordance and this analysis was not performed. This approach of performing PD-L1 testing on one biopsy specimen was designed to preserve tumor cells within the specimen for potential molecular testing at the discretion of the treating oncologist. Adequacy of tissue for molecular and NGS was determined in an identical manner as for PD-L1 above.

All demographic, clinical, pathology, surgical, and procedural data were recorded following review of the electronic medical record. Variables collected included: age, gender, smoking, history, subtype of non-small cell carcinoma, size of nodule or mass, position emission tomography (PET) standard uptake value (SUV) of target nodule or mass, stage of NSCLC, tumor size classification (T1, T2, T3 or T4), location of nodule or mass, presence of bronchus sign (Yes/No, defined by visible airway directly to the center or adjacent to the lesion); adequacy (Yes/No) for PD-L1 expression and percentage of expression $(<1 \%$, $1-49 \%$, >50\%); surgical PD-L1 expression if performed, adequacy (Yes/No) for molecular testing (e.g., EGFR, ALK, ROS-1) and next generation sequency, REBUS used (Yes/No), biopsy tools used [transbronchial needle aspiration (TBNA), brush, transbronchial biopsy (TBBX), bronchoalveolar lavage], number of passes with the biopsy tools, and need for additional biopsy procedure and the reason why additional biopsy procedure was performed. Complications as reported by a previous national quality improvement project that included pneumothorax, pneumothorax requiring chest tube, unplanned admission, bleeding requiring advanced intervention, and respiratory failure were recorded (18).

\section{Statistical analysis}

The primary outcome was determined by calculating the ratio of patients with $\mathrm{PD}-\mathrm{L} 1$ expression divided by the total number of patients with pathology data available. Missing data was excluded in this calculation. The association of clinical and procedural factors with PD-L1 adequacy was evaluated in both adjusted and un-adjusted analyses. Candidate variables selected a priori included patient age, gender, smoking status, size of tumor, REBUS use, stage of cancer, tumor status, bronchus sign (on CT scan imaging), TBBX, PET scan and PET avidity in SUV because these have been shown to predict higher diagnostic yield for bronchoscopy, which may in turn yield a higher adequacy rate for PD-L1 expression. Rate ratios (RR) for PD-L1 adequacy were estimated using modified Poisson regression models with robust standard errors. Multicollinearity was evaluated by variance inflation factors (all <2.2). Missing data was imputed using multiple imputation by chained equations. The imputation model included all outcomes and predictor variables; continuous variables were imputed using predictive mean matching, and categorical variables were imputed using cumulative link or multinomial regression. One hundred randomly imputed data sets were generated; models were fit on each data set and results were pooled using Rubin's rule to obtain final model estimates, confidence intervals and $\mathrm{P}$ values. Analyses were performed using SAS version 9.4 and $\mathrm{R}$ version 3.6.3.

\section{Results}

A total of 102 patients who underwent a NB procedure and had a diagnosis of NSCLC were analyzed over a 2-year period. Only 1 patient underwent REBUS plus fluoroscopy without EMN. Thus, $99 \%$ of the study population was comprised of patients who underwent EMN bronchoscopy specifically. Fifty-two patients (51\%) were male and the mean [standard deviation (SD)] age was 71.0 years (SD: 9.9); $85 \%$ of patients were current or former smokers. A PET scan was performed in $90 \%(92 / 102)$ of patients and the target nodule/mass was PET positive in $90 \%$ of cases (82/102). The mean (SD) standard uptake value of the biopsied nodules was 10 (SD: 5.9). The most common type of NSCLC was adenocarcinoma [59.8\%, (61/102)] followed by squamous cell carcinoma $[28 \%,(29 / 102)]$ and the majority were stage $1-2(75 \%, 77 / 102)$ (Table 1$)$.

Of the entire cohort of 102 patients, 9 specimens were missing data to determine sample adequacy. Of the 93 remaining samples, 68 were adequate for PD-L1 testing. Thus, $73.1 \%$ (68/93) of available samples were adequate for PD-L1 testing. A total of 53\% (36/68) of patients had a PD-L1 expression of $<1 \%, 25 \%$ (17/68) had expression of $1-49 \%$, and $22 \%(15 / 68)$ had expression of $>50 \%$.

Data for evaluating tissue adequacy for molecular testing was available in $95 \%(97 / 102)$ of patients and was performed on $12.4 \%(12 / 97)$ of patients [not indicated in $88 \%(85 / 97)$ of patients], $58 \%(7 / 12)$ of which had adequate 
Table 1 Demographic, clinical, and procedural characteristics

\begin{tabular}{|c|c|}
\hline Variable & Total $(n=102)$ \\
\hline \multicolumn{2}{|l|}{ Age } \\
\hline Mean \pm SD & $71.2 \pm 9.9$ \\
\hline Median (IQR) & $73.0(63.0,78.0)$ \\
\hline Range & $45.0-88.0$ \\
\hline Gender, female, n (\%) & $52(51.0)$ \\
\hline \multicolumn{2}{|l|}{ Smoking history, n (\%) } \\
\hline Current & $32(31.7)$ \\
\hline Never & $14(13.9)$ \\
\hline Former & $55(54.5)$ \\
\hline Missing & 1 \\
\hline \multicolumn{2}{|l|}{ Type of lung cancer, $\mathrm{n}(\%)$} \\
\hline Adenocarcinoma & $61(59.8)$ \\
\hline Squamous cell carcinoma & $29(28.4)$ \\
\hline Mixed adenocarcinoma-squamous cell & $1(1.0)$ \\
\hline Poorly differentiated non-small cell carcinoma & $2(2.0)$ \\
\hline Other non-small cell carcinoma & $9(8.8)$ \\
\hline Adequate material for PD-L1, n (\%) & $68(73.1)$ \\
\hline Missing & 9 \\
\hline \multicolumn{2}{|l|}{ Surgical specimen for PD-L1 reported, n (\%) } \\
\hline Yes & $15(14.9)$ \\
\hline No & $27(26.7)$ \\
\hline N/A-surgery not performed & $59(58.4)$ \\
\hline Missing & 1 \\
\hline \multicolumn{2}{|l|}{ PD-L1 expression, n (\%) } \\
\hline$<1 \%$ & $36(52.9)$ \\
\hline $1-49 \%$ & $17(25.0)$ \\
\hline$>50 \%$ & $15(22.1)$ \\
\hline Missing & 34 \\
\hline \multicolumn{2}{|l|}{ Surgical PD-L1 expression, $n(\%)$} \\
\hline$<1 \%$ & $8(53.3)$ \\
\hline $1-49 \%$ & $6(40.0)$ \\
\hline$>50 \%$ & $1(6.7)$ \\
\hline Missing & 87 \\
\hline
\end{tabular}

Table 1 (continued)
Table 1 (continued)

\begin{tabular}{|c|c|}
\hline Variable & Total $(n=102)$ \\
\hline \multicolumn{2}{|c|}{ Adequate for molecular analysis, $\mathrm{n}(\%)$} \\
\hline Yes & $7(7.2)$ \\
\hline No & $5(5.2)$ \\
\hline Not applicable & $85(87.6)$ \\
\hline Missing & 5 \\
\hline \multicolumn{2}{|c|}{ Adequate material for NGS, $\mathrm{n}(\%)$} \\
\hline Yes & $8(8.2)$ \\
\hline No & $5(5.2)$ \\
\hline Not applicable & $84(86.6)$ \\
\hline Missing & 5 \\
\hline REBUS used, $n(\%)$ & $101(99.0)$ \\
\hline \multicolumn{2}{|l|}{ REBUS view, n (\%) } \\
\hline Concentric & $79(78.2)$ \\
\hline Eccentric & $17(16.8)$ \\
\hline No view & $5(5.0)$ \\
\hline Missing & 1 \\
\hline \multicolumn{2}{|l|}{ Nodule size (mm) } \\
\hline Mean \pm SD & $26.9 \pm 12.7$ \\
\hline Median (IQR) & $25.0(18.0,32.0)$ \\
\hline \multicolumn{2}{|c|}{ Stage of lung cancer, n (\%) } \\
\hline Stage 1a & $54(52.9)$ \\
\hline Stage $1 b$ & $7(6.9)$ \\
\hline Stage $2 a$ & $7(6.9)$ \\
\hline Stage $2 b$ & $9(8.8)$ \\
\hline Stage 3a & $8(7.8)$ \\
\hline Stage 3b & $5(4.9)$ \\
\hline Stage 4 & $12(11.8)$ \\
\hline \multicolumn{2}{|l|}{ Tumor status, n (\%) } \\
\hline $1 a$ & $4(3.9)$ \\
\hline $1 b$ & $25(24.5)$ \\
\hline $1 c$ & 39 (38.2) \\
\hline 2 & $14(13.7)$ \\
\hline $2 a$ & $5(4.9)$ \\
\hline
\end{tabular}

Table 1 (continued) 
Table 1 (continued)

\begin{tabular}{|c|c|}
\hline Variable & Total $(n=102)$ \\
\hline $2 b$ & $6(5.9)$ \\
\hline 3 & $6(5.9)$ \\
\hline 4 & $2(2.0)$ \\
\hline $\mathrm{T} 4$ & $1(1.0)$ \\
\hline \multicolumn{2}{|l|}{ Location of nodule, $\mathrm{n}(\%)$} \\
\hline Right upper lobe & $39(38.2)$ \\
\hline Right middle lobe & $6(5.9)$ \\
\hline Right lower lobe & $16(15.7)$ \\
\hline Left upper lobe & $30(29.4)$ \\
\hline Left lower lobe & $11(10.8)$ \\
\hline Bronchus sign, $\mathrm{n}(\%)$ & $59(57.8)$ \\
\hline TBNA, n (\%) & $102(100.0)$ \\
\hline \multicolumn{2}{|l|}{ Number of needle passes, $\mathrm{n}(\%)$} \\
\hline $1-5$ & $18(17.6)$ \\
\hline $6-10$ & $75(73.5)$ \\
\hline$>10$ & $9(8.8)$ \\
\hline Transbronchial biopsy, n (\%) & $94(92.2)$ \\
\hline \multicolumn{2}{|l|}{ Number of biopsies, n (\%) } \\
\hline $1-4$ & $1(1.1)$ \\
\hline $5-10$ & $90(96.8)$ \\
\hline$>10$ & $2(2.2)$ \\
\hline Missing & 9 \\
\hline Brush, n (\%) & $63(61.8)$ \\
\hline Bronchoalveolar lavage, n (\%) & $73(71.6)$ \\
\hline PET scan performed, $\mathrm{n}(\%)$ & $92(90.2)$ \\
\hline PET avid (> or equal to 2.5 SUV), $n$ (\%) & $82(90.1)$ \\
\hline Missing & 11 \\
\hline \multicolumn{2}{|l|}{ PET avidity in SUV, $\mathrm{n}(\%)$} \\
\hline Mean \pm SD & $10.3 \pm 5.9$ \\
\hline Median (IQR) & $8.5(5.9,14.0)$ \\
\hline Missing & 20 \\
\hline Additional biopsy performed, n (\%) & $4(3.9)$ \\
\hline
\end{tabular}

Table 1 (continued)
Table 1 (continued)

\begin{tabular}{|c|c|}
\hline Variable & Total $(n=102)$ \\
\hline \multicolumn{2}{|l|}{ Type of additional biopsy, n (\%) } \\
\hline CT guided biopsy & $1(25.0)$ \\
\hline Surgical biopsy & $1(25.0)$ \\
\hline Other $^{\mathrm{a}}$ & $2(50.0)$ \\
\hline $\begin{array}{l}\text { Reason for additional biopsy (no enough tissue } \\
\text { for lung cancer subtype classification), } \mathrm{n}(\%)\end{array}$ & $0(0.0)$ \\
\hline $\begin{array}{l}\text { Reason for additional biopsy (not enough tissue } \\
\text { for molecular testing on bronchoscopy), } \mathrm{n}(\%)\end{array}$ & $4(3.9)$ \\
\hline \multicolumn{2}{|c|}{$\begin{array}{l}\text { a, } 1 \text { with Guardant blood test; } 1 \text { with Inivata liquid biopsy } \\
\text { (negative for ALK, RET, ROS-1, NGS panel negative). Guardant } \\
\text { and Inivata are both NGS tests. SD, standard deviation; IQR, } \\
\text { interquartile range; PD-L1, programmed death-ligand 1; NGS, } \\
\text { next generation sequencing; REBUS, radial endobronchial } \\
\text { ultrasound; TBNA, transbronchial needle aspiration; PET, } \\
\text { position emission tomography; SUV, standard uptake value; CT, } \\
\text { computed tomography. }\end{array}$} \\
\hline
\end{tabular}

Table 2 NB and surgical biopsies PD-L1 expression

\begin{tabular}{ccc}
\hline \multirow{2}{*}{ Case } & \multicolumn{2}{c}{ PD-L1 expression } \\
\cline { 2 - 3 } & Surgical biopsy & Bronchoscopy biopsy \\
\hline 1 & $1-49 \%$ & $<1 \%$ \\
2 & $<1 \%$ & $<1 \%$ \\
3 & $<1 \%$ & $1-49 \%$ \\
4 & $<1 \%$ & $<1 \%$ \\
\hline
\end{tabular}

NB, navigational bronchoscopy; PD-L1, programmed deathligand 1.

tissue samples for processing. Data for evaluating tissue adequacy for NGS was present in 95\% (97/102) of patients and was performed on $13.4 \%(13 / 97)$ of patients [not indicated in $86.6 \%(84 / 97)$ of patients], of whom $61.5 \%$ $(8 / 13)$ had adequate tissue for NGS processing.

Surgery was not performed in 58\% (59/102) of patients and PD-L1 testing was reported in only $15 \%$ of the remaining $42 \%$ of patients who had surgery (Table 1). Only 4 patients had both surgical and bronchoscopy data on the same sample. Of those four patients, half had identical PDL1 expression (Table 2). 
In regards to procedural related variables, the mean (SD) nodule size was $26 \mathrm{~mm}$ (SD: 12.7 ) and $58 \%$ had a bronchus sign (59/102). TBNA and TBBX was performed in $100 \%$ and $94 \%$ of the procedures, respectively. Five to ten TBBXs were performed in 97\% of cases and 6-10 TBNA passes were performed in $74 \%$ of procedures (Table 1 ). Complications were minimal. One pneumothorax occurred requiring a chest tube that resulted in overnight admission. However, there was no bleeding requiring advanced intervention or respiratory failure that occurred in the study population.

Only 4\% (4/102) of patients required an additional biopsy when it was felt clinically indicated, which was universally due to low tumor volume sample for PD-L1 processing.

Overall, there was no association between clinical or procedural variables and PD-L1 yield in either unadjusted or adjusted analysis (Table 3 and Figure 1). Specifically, neither nodule size ( $\mathrm{RR}=1.02 ; 95 \% \mathrm{CI}$ : $0.87-1.20 ; \mathrm{P}=0.83$ ) or presence of bronchus sign ( $\mathrm{RR}=1.13$; $95 \%$ CI: $0.88-1.46$; $\mathrm{P}=0.34$ ) was associated with higher probability of adequate tissue for PD-L1. Transbronchial biopsy had a RR of 4.16 but did not reach statistical significance (95\% CI: $0.71-$ 24.29; $\mathrm{P}=0.11$ ).

\section{Discussion}

In our retrospective review of $102 \mathrm{NB}$ procedures with a diagnosis of NSCLC, in which 93 had complete data, adequate samples for PD-L1 testing were obtained in $73 \%$ of patients. In this cohort in which most patients were stage 1-2 adenocarcinomas, the majority of $\mathrm{PD}$ L1 expression (53\%) was $<1$. Data on adequacy for molecular profile testing and NGS from NB specimens was limited and modest with roughly $60 \%$ of tested specimens being of sufficient quality to be processed for both types of testing. No predictive factors were found between clinical or procedural variables and tissue adequacy for PD-L1 testing. Due to institutional practice of performing PD-L1 testing on one biopsy specimen, limited data was available to compare concordance rates between bronchoscopy and surgical biopsy specimens. Of most clinical importance, only $4 \%$ of patients required a repeat procedure due to insufficient tissue obtained on a NB procedure.

The majority of diagnostic bronchoscopy studies to date have reported on the proficiency of NB in obtaining tissue for molecular markers with a reasonable degree of success.
A study by Moon et al. (11) reported EGFR testing on 92 patients diagnosed with adenocarcinoma by REBUS and transbronchial biopsy. Of the 92 patients, $65 \%$ underwent EGFR testing of which it was successful in $98 \%$. Sánchez-Font and colleagues reported a $100 \%$ tissue adequacy rate for EGFR and KRAS on REBUS guided cytology brushing specimens in 30 patients with a diagnosis of adenocarcinoma (10). Similarly, in a study of 111 non-squamous, NSCLC patients, $88 \%$ had sufficient tissue for molecular testing (EGFR, ALK, KRAS, BRAF, HER2, PIK3CA) (8). Finally the prospective NAVIGATE study reported $86 \%$ (75/87) of samples suitable for molecular testing (9).

However, little information is available for PD-L1 analysis from $\mathrm{NB}$ guided tissue samples. The studies to date have mainly chosen a small subset of the total population of NSCLC patients to answer a specific question. For example, in the aforementioned study by Moon and co-workers, of the 92 patients with adenocarcinoma, only 17 underwent PD-L1 testing, of which 16/17 were successfully processed. Similarly, in another study by Kitazono and colleagues which evaluated concordance rates between guided bronchoscopy specimens and surgical biopsies for PD-L1 expression, 19\% (71/378) of the total cohort were chosen, all of which had suitable testing for PD-L1 (13). In the largest study to date on this subject by Robin et al. (14), a feasibility rate for PDL1 of $94 \%$ was reported in a cohort of 231 patients who were tested for PD-L1. In this study, roughly $65 \%$ were advanced staged lung cancer, EMN was utilized in $4 \%$ (14/331) of bronchoscopies and $36 \%$ of the target lesions were $<3 \mathrm{~cm}$ in size. In addition, no factors associated with a successful PD-L1 analysis was reported. In comparison, $60 \%$ of patients in our study were stage 1,99\% of bronchoscopies were performed with EMN technology and the median nodule size was $2.5 \mathrm{~cm}$ with only $58 \%$ having a bronchus sign. While no factors predictive of PD-L1 adequacy, our study did demonstrate that testing is successful in patients with small nodules via an EMN platform.

Our study did not demonstrate clinical or procedural factors predictive of adequate tissue for PD-L1. We suspect this is due to insufficient power as our current sample size, considering $80 \%$ power, would detect RR only greater than 2.8 given a $50 \%$ prevalence of PD-L1 adequacy. Thus, two times the number of patients would be needed to identify predictive factors.

Limited data was available to compare concordance rates between bronchoscopy and surgical biopsy specimens. Of the 4 patients with data, half had concordant results. Accuracy of PD-L1 reporting is important to consider given 
Table 3 Variables associated with adequate tissue for PD-L1: unadjusted analysis

\begin{tabular}{|c|c|c|c|}
\hline Variable & \multicolumn{2}{|c|}{ Adequate material for PD-L1 } & $P$ value \\
\hline Age, n (\%) & & & 0.800 \\
\hline Quartile 1 (45 to 62 ) & $12(63.2)$ & $7(36.8)$ & \\
\hline Quartile 2 (63 to 72 ) & $21(77.8)$ & $6(22.2)$ & \\
\hline Quartile 4 (78 to 88 ) & $18(66.7)$ & 9 (33.3) & \\
\hline Gender, n (\%) & & & 0.801 \\
\hline Female & $34(75.6)$ & $11(24.4)$ & \\
\hline Male & $34(70.8)$ & $14(29.2)$ & \\
\hline Never & $9(69.2)$ & $4(30.8)$ & \\
\hline Former & $37(74.0)$ & $13(26.0)$ & \\
\hline REBUS view, n (\%) & & & 0.204 \\
\hline Concentric & $56(77.8)$ & $16(22.2)$ & \\
\hline Eccentric & $8(53.3)$ & $7(46.7)$ & \\
\hline No view & $3(60.0)$ & $2(40.0)$ & \\
\hline Nodule size (mm), n (\%) & & & 0.240 \\
\hline Quartile 1 (10.0 to 17.9 ) & $12(57.1)$ & $9(42.9)$ & \\
\hline $3-4$ & 19 (79.2) & $5(20.8)$ & \\
\hline Tumor status, n (\%) & & & 0.585 \\
\hline 1 & $45(72.6)$ & $17(27.4)$ & \\
\hline $2-4$ & $23(74.2)$ & $8(25.8)$ & \\
\hline Bronchus sign, n (\%) & & & 0.151 \\
\hline Yes & $43(78.2)$ & $12(21.8)$ & \\
\hline No & $25(65.8)$ & $13(34.2)$ & \\
\hline Transbronchial biopsy, n (\%) & & & 0.100 \\
\hline Yes & $67(76.1)$ & $21(23.9)$ & \\
\hline No & $1(20.0)$ & $4(80.0)$ & \\
\hline
\end{tabular}

Table 3 (continued) 
Table 3 (continued)

\begin{tabular}{|c|c|c|c|}
\hline Variable & \multicolumn{2}{|c|}{ Adequate material for PD-L1 } & $P$ value \\
\hline PET scan performed, n (\%) & & & 0.906 \\
\hline Yes & $61(73.5)$ & $22(26.5)$ & \\
\hline No & $7(70.0)$ & $3(30.0)$ & \\
\hline Quartile 1 (2.50 to 5.89 ) & $11(64.7)$ & $6(35.3)$ & \\
\hline Quartile 2 (5.90 to 8.44) & $14(73.7)$ & $5(26.3)$ & \\
\hline Quartile 3 (8.45 to 13.99 ) & $14(87.5)$ & $2(12.5)$ & \\
\hline Quartile 4 (14.00 to 29.00 ) & $16(76.2)$ & $5(23.8)$ & \\
\hline
\end{tabular}

Continuous variables compared using Student's $t$-test. Categorical variables compared using chi-square or Fisher's exact test. PD-L1, programmed death-ligand 1; REBUS, radial endobronchial ultrasound; PET, position emission tomography; SUV, standard uptake value.

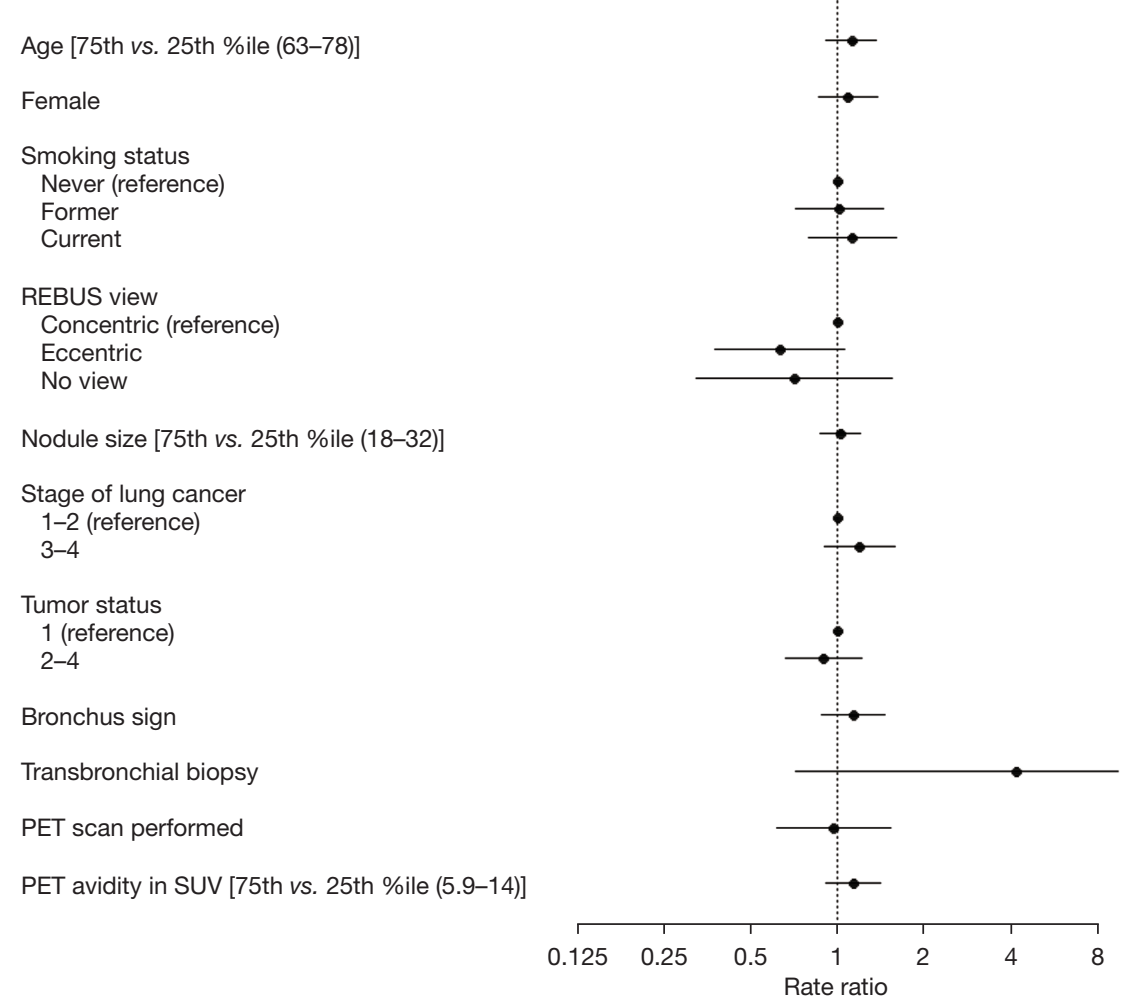

\begin{tabular}{|c|c|}
\hline $1.11(0.91,1.36)$ & $P=0.29$ \\
\hline $1.08(0.86,1.37)$ & $P=0.50$ \\
\hline $\begin{array}{l}1.00 \\
1.01(0.71,1.45) \\
1.12(0.79,1.60)\end{array}$ & $P=0.70$ \\
\hline $\begin{array}{l}1.00 \\
0.63(0.37,1.05) \\
0.70(0.32,1.54)\end{array}$ & $P=0.14$ \\
\hline $1.02(0.87,1.20)$ & $P=0.83$ \\
\hline $\begin{array}{l}1.00 \\
1.19(0.90,1.58)\end{array}$ & $P=0.23$ \\
\hline $\begin{array}{l}1.00 \\
0.89(0.66,1.21)\end{array}$ & $P=0.45$ \\
\hline $1.13(0.88,1.46)$ & $P=0.34$ \\
\hline $4.16(0.71,24.29)$ & $P=0.11$ \\
\hline $0.97(0.61,1.52)$ & $P=0.88$ \\
\hline $1.13(0.91,1.41)$ & $P=0.27$ \\
\hline
\end{tabular}

Figure 1 Forrest plot for adjusted associations with adequate PD-L1 expression. RR reported with (95\% CI). REBUS, radial endobronchial ultrasound; PET, position emission tomography; SUV, standardized uptake values; RR, rate ratio; PD-L1, programmed death-ligand 1. 
known intratumoral heterogeneity with PD-L1 expression. Data on EBUS-TBNA has shown good concordance and predictive value with surgical specimens when PD$\mathrm{L} 1$ expression is $>1 \%$ but falls when is PD-L1 expression $>50 \%$, raising concerns of adequate tissue sampling (19). Initial data on concordance between NB and surgical biopsies appears promising, however. Kitazono et al. (13) showed a concordance rate of $92 \%$ on 71 biopsy specimens using IHC score assessment; however, the concordance rate dropped as PD-L1 expression increased to $>50 \%$. Thus, the question of the sensitivity of small cytological and histological samples obtained via NB remains unanswered and more studies are needed.

Our study showed modest performance of NB on the yield of tissue for molecular and NGS testing compared to prior studies with $60 \%$ reported tissue adequacy. The reasons for this are probably multi-factorial and related to a combination of tissue processing and handling and biopsy tools and techniques. It is important that clear communication exists between the bronchoscopist and cytopathologist/cytotechnologist to ensure that tissue is preserved as much as possible for ancillary testing. Given the retrospective design, we were not able to account if this type of communication occurred. Guidelines have been developed for EBUS-TBNA and transthoracic needle biopsies to optimize diagnosis and tissue acquisition for ancillary studies and which may provide guidance for bronchoscopists when sampling peripheral pulmonary nodules. These include routine use of ROSE and limiting passes to 3-5 with use of TBNA techniques. While needle size has not been shown to yield greater tissue acquisition with EBUS TBNA it remains to be seen whether this holds true for sampling peripheral pulmonary nodules $(20,21)$. Our study was not designed to evaluate in detail the reasons for inadequate tissue and this would require further study.

The performance of NB in acquiring adequate tissue for PD-L1 processing in our study is good but needs improvement. We routinely use a $21-\mathrm{G}$ needle and small biopsy forceps $(1.7 \mathrm{~mm}$ outer diameter and $8 \mathrm{~mm}$ in length, Supertrax, Medtronic). Larger tools may be necessary; however, these frequently are stiff and cause EMN catheter deflection, leading to a biopsy miss of the nodule/mass. Newer technologies that achieve greater catheter stability and prevent deflection may resolve this issue $(22,23)$. Ideally, a biopsy procedure should provide sufficient tissue to avoid a repeat biopsy. While one could interpret our results in that $27 \%$ of patients may need a repeat biopsy, in actuality, only $4 \%$ required an additional biopsy when this was clinically indicated by the treating oncologist. However, every effort should be made to obtain sufficient tissue and further study on biopsy instruments and tissue handling and processing needs to be performed.

Our study has important limitations. The retrospective nature introduces bias as to patient selection, the number and type of biopsies that were performed depending on the size and location of nodule/mass. However, no patients were excluded as all consecutive patients who underwent $\mathrm{NB}$ and had a confirmed diagnosis of non-small cell carcinoma were analyzed. Two different bronchoscopists performed the procedures and the sampling method was not consistently standardized between them, possibly influencing the results. The limited surgical data for PD-L1 comparison impairs our ability to comment on accurate PD-L1 tissue expression in small biopsy specimens and, until further data is available, our results do not promote bronchoscopy biopsy specimens over larger biopsies if there is a clinical concern for accurate intratumoral heterogeneity. As mentioned above, the study is underpowered to detect factors associated with PD-L1 tissue adequacy. Hopefully, results from ongoing prospective bronchoscopy studies can be gleaned to provide such data [VERITAS (NCT04250194); TARGET (NTCT04182815)].

In summary, NB has good performance in obtaining sufficient tissue for PD-L1 processing. No factors were associated with PD-L1 tissue adequacy; however, further study is needed in this regard particularly in comparison to surgical biopsy specimens. Additional data is needed to evaluate concordance of NB biopsies and surgical specimens with PD-L1 expression.

\section{Acknowledgments}

This work was presented as an abstract at the American Thoracic Society International Conference, May 2021. Funding: None.

\section{Footnote}

Reporting Checklist: The authors have completed the STROBE reporting checklist. Available at https://jtd. amegroups.com/article/view/10.21037/jtd-21-1454/rc

Data Sharing Statement: Available at https://jtd.amegroups. com/article/view/10.21037/jtd-21-1454/dss

Conflicts of Interest: All authors have completed the ICMJE 
uniform disclosure form (available at https://jtd.amegroups. com/article/view/10.21037/jtd-21-1454/coif). TS is an educational speaker for Medtronic. TS has received speaking fees from OncLive, Veracyte and Biodesix, not related to this work. MA received speaking fees and performs educational work for Medtronic. The other authors have no conflicts of interest to declare.

Ethical Statement: The authors are accountable for all aspects of the work in ensuring that questions related to the accuracy or integrity of any part of the work are appropriately investigated and resolved. The study was conducted in accordance with the Declaration of Helsinki (as revised in 2013). The study was approved by Saint Luke's Health System institutional review board of IRB \#SLHS20-118 and individual consent for this retrospective analysis was waived.

Open Access Statement: This is an Open Access article distributed in accordance with the Creative Commons Attribution-NonCommercial-NoDerivs 4.0 International License (CC BY-NC-ND 4.0), which permits the noncommercial replication and distribution of the article with the strict proviso that no changes or edits are made and the original work is properly cited (including links to both the formal publication through the relevant DOI and the license). See: https://creativecommons.org/licenses/by-nc-nd/4.0/.

\section{References}

1. Antonia S, Goldberg SB, Balmanoukian A, et al. Safety and antitumour activity of durvalumab plus tremelimumab in non-small cell lung cancer: a multicentre, phase $1 \mathrm{~b}$ study. Lancet Oncol 2016;17:299-308.

2. Borghaei H, Paz-Ares L, Horn L, et al. Nivolumab versus Docetaxel in Advanced Nonsquamous Non-Small-Cell Lung Cancer. N Engl J Med 2015;373:1627-39.

3. Fehrenbacher L, Spira A, Ballinger M, et al. Atezolizumab versus docetaxel for patients with previously treated non-small-cell lung cancer (POPLAR): a multicentre, open-label, phase 2 randomised controlled trial. Lancet 2016;387:1837-46.

4. Herbst RS, Baas P, Kim DW, et al. Pembrolizumab versus docetaxel for previously treated, PD-L1-positive, advanced non-small-cell lung cancer (KEYNOTE-010): a randomised controlled trial. Lancet 2016;387:1540-50.

5. Reck M, Rodríguez-Abreu D, Robinson AG, et al. Pembrolizumab versus Chemotherapy for PD-L1-
Positive Non-Small-Cell Lung Cancer. N Engl J Med 2016;375:1823-33.

6. Beattie J, Yarmus L, Wahidi M, et al. The Immune Landscape of Non-Small-Cell Lung Cancer. Utility of Cytologic and Histologic Samples Obtained through Minimally Invasive Pulmonary Procedures. Am J Respir Crit Care Med 2018;198:24-38.

7. Tajarernmuang P, Ofiara L, Beaudoin S, et al. Bronchoscopic tissue yield for advanced molecular testing: are we getting enough? J Thorac Dis 2020;12:3287-95.

8. Guisier F, Salaün M, Lachkar S, et al. Molecular analysis of peripheral non-squamous non-small cell lung cancer sampled by radial EBUS. Respirology 2016;21:718-26.

9. Folch EE, Pritchett MA, Nead MA, et al. Electromagnetic Navigation Bronchoscopy for Peripheral Pulmonary Lesions: One-Year Results of the Prospective, Multicenter NAVIGATE Study. J Thorac Oncol 2019;14:445-58.

10. Sánchez-Font A, Chalela R, Martín-Ontiyuelo C, et al. Molecular analysis of peripheral lung adenocarcinoma in brush cytology obtained by EBUS plus fluoroscopy-guided bronchoscopy. Cancer Cytopathol 2018;126:860-71.

11. Moon SM, Choe J, Jeong BH, et al. Diagnostic Performance of Radial Probe Endobronchial Ultrasound without a Guide-Sheath and the Feasibility of Molecular Analysis. Tuberc Respir Dis (Seoul) 2019;82:319-27.

12. Ilie M, Long-Mira E, Bence C, et al. Comparative study of the PD-L1 status between surgically resected specimens and matched biopsies of NSCLC patients reveal major discordances: a potential issue for anti-PD-L1 therapeutic strategies. Ann Oncol 2016;27:147-53.

13. Kitazono S, Fujiwara Y, Tsuta K, et al. Reliability of Small Biopsy Samples Compared With Resected Specimens for the Determination of Programmed Death-Ligand 1 Expression in Non--Small-Cell Lung Cancer. Clin Lung Cancer 2015;16:385-90.

14. Robin M, Mhanna L, Chaltiel L, et al. Feasibility of comprehensive genotyping specimens from radial endobronchial ultrasonography and electromagnetic navigation bronchoscopy. ERJ Open Res 2021;7:e00942-2020.

15. Karnik T, Kimler BF, Fan F, et al. PD-L1 in breast cancer: comparative analysis of 3 different antibodies. Hum Pathol 2018;72:28-34.

16. Hirsch FR, McElhinny A, Stanforth D, et al. PDL1 Immunohistochemistry Assays for Lung Cancer: Results from Phase 1 of the Blueprint PD-L1 IHC Assay Comparison Project. J Thorac Oncol 2017;12:208-22.

17. Ratcliffe MJ, Sharpe A, Midha A, et al. Agreement between 
Programmed Cell Death Ligand-1 Diagnostic Assays across Multiple Protein Expression Cutoffs in Non-Small Cell Lung Cancer. Clin Cancer Res 2017;23:3585-91.

18. Ost DE, Ernst A, Lei X, et al. Diagnostic Yield and Complications of Bronchoscopy for Peripheral Lung Lesions. Results of the AQuIRE Registry. Am J Respir Crit Care Med 2016;193:68-77.

19. Sakata KK, Midthun DE, Mullon JJ, et al. Comparison of Programmed Death Ligand-1 Immunohistochemical Staining Between Endobronchial Ultrasound Transbronchial Needle Aspiration and Resected Lung Cancer Specimens. Chest 2018;154:827-37.

20. van der Heijden EH, Casal RF, Trisolini R, et al. Guideline for the acquisition and preparation of conventional and endobronchial ultrasound-guided transbronchial needle aspiration specimens for the diagnosis and molecular testing of patients with known or suspected lung cancer. Respiration 2014;88:500-17.

21. Roy-Chowdhuri S, Dacic S, Ghofrani M, et al. Collection and Handling of Thoracic Small Biopsy and Cytology Specimens for Ancillary Studies: Guideline From the College of American Pathologists in Collaboration With the American College of Chest Physicians, Association for Molecular Pathology, American Society of Cytopathology, American Thoracic Society, Pulmonary Pathology Society, Papanicolaou Society of Cytopathology, Society of Interventional Radiology, and Society of Thoracic Radiology. Arch Pathol Lab Med 2020. [Epub ahead of print]. doi: 10.5858/arpa.2020-0119-CP.

22. Chaddha U, Kovacs SP, Manley C, et al. Robot-assisted bronchoscopy for pulmonary lesion diagnosis: results from the initial multicenter experience. BMC Pulm Med 2019;19:243.

23. Fielding DIK, Bashirzadeh F, Son JH, et al. First Human Use of a New Robotic-Assisted Fiber Optic Sensing Navigation System for Small Peripheral Pulmonary Nodules. Respiration 2019;98:142-50.

Cite this article as: Asad H, Saettele T, Tawfik O, Jones P, Aboudara M. Navigational bronchoscopy specimens and PDL1 expression: a retrospective study. J Thorac Dis 2022;14(2):295305. doi: $10.21037 /$ jtd-21-1454 